\title{
Improvement of Transpassive Intergranular Corrosion Resistance of 304 Austenitic Stainless Steel by Thermomechanical Processing for Twin-induced Grain Boundary Engineering
}

\author{
Wei Zhong JIN, ${ }^{1)}$ Hiroyuki KOKAWA, ${ }^{2)}$ Zhan Jie WANG, ${ }^{3)}$ Yutaka S. SATO ${ }^{21}$ and Nobuyoshi HARA ${ }^{4)}$ \\ 1) Formerly Department of Materials Processing, Graduate School of Engineering, Tohoku University, 6-6-02 Aramaki-aza- \\ Aoba, Aoba-ku, Sendai 980-8579 Japan. Now at Silicon Steel Department, Baoshan Iron \& Steel Co., Ltd., China. \\ 2) Department of Materials Processing, Graduate School of Engineering, Tohoku University, 6-6-02 Aramaki-aza-Aoba, Aoba- \\ ku, Sendai 980-8579 Japan. $\quad$ 3) Formerly Department of Materials Science, Graduate School of Engineering, Tohoku \\ University, 6-6-02 Aramaki-aza-Aoba, Aoba-ku, Sendai 980-8579 Japan. Now at Institute of Metal Research, Chinese Academy \\ of Sciences, China. $\quad$ 4) Department of Materials Science, Graduate School of Engineering, Tohoku University, 6-6-02 \\ Aramaki-aza-Aoba, Aoba-ku, Sendai 980-8579 Japan.
}

(Received on October 2, 2009; accepted on December 14, 2009)

\begin{abstract}
Grain boundary engineering (GBE) primarily aims to prevent the initiation and propagation of intergranular degradation along grain boundaries by frequent introduction of coincidence site lattice (CSL) boundaries into the grain boundary networks in materials. It has been reported that GBE is effective to prevent passive intergranular corrosion such as sensitization of austenitic stainless steels, but the effect of GBE on transpassive corrosion has not been clarified. In the present study, a twin-induced GBE utilizing optimized thermomechanical processing with small pre-strain and subsequent annealing was applied to introduce very high frequencies of CSL boundaries into type 304 austenitic stainless steels containing different phosphorus concentrations. The resulting steels showed much higher resistance to transpassive intergranular corrosion during the Coriou test, in comparison with the as-received ones. The high CSL frequency resulted in a very low percolation probability of random boundary networks in the over-threshold region and remarkable suppression of intergranular deterioration during GBE.
\end{abstract}

KEY WORDS: grain boundary engineering; coincidence site lattice; thermomechanical processing; austenitic stainless steel; intergranular corrosion.

\section{Introduction}

Intergranular degradation often limits the lifetime and reliability of polycrystalline structural materials. In spite of persistent efforts to prevent such degradation, its complete suppression has not yet been achieved. Grain boundary studies have revealed that grain boundary phenomena strongly depend on the grain boundary structure and character. $^{1-5)}$ It is generally accepted that low-energy boundaries such as coincidence site lattice (CSL) boundaries, are highly resistant to deterioration, as contrasted with high-energy boundaries such as random boundaries. The concept of "grain boundary design and control"6) has been developed and refined as grain boundary engineering (GBE). ${ }^{7)}$ GBE primarily aims to prevent the initiation and propagation of intergranular degradation along random boundaries by frequent introduction of CSL boundaries into the grain boundary networks in materials. Recent GBE investigations $^{8-17)}$ have been promoting a new innovative approach for suppression of the intergranular degradation phenomena such as intergranular cracking, intergranular corrosion, etc., which can lead to destruction of polycrystalline material structures before their design service life. Many GBE in- vestigations have dealt with face-centered cubic materials with low stacking fault energy which leads to frequent generation of annealing twins. Suitable thermomechanical processing increases the frequency of CSL boundaries and results in a desirable grain boundary character distribution (GBCD) with disconnected random boundaries being produced in the material by twin-emissions and boundaryboundary reactions during annealing. ${ }^{11,15)}$ Optimized GBCD has demonstrated a high resistance to intergranular corrosion due to sensitization in austenitic stainless steels. ${ }^{11,15-17)}$ A recent review ${ }^{18)}$ of the twinning-related GBE introduced many grain boundary engineered materials (GBEMs) which showed improvement in properties. The review states that the highest frequency $(87 \%)$ of CSL boundaries in structural materials was achieved by the GBE of a 304 austenitic stainless steel. ${ }^{11)}$ The GBEM of 304 stainless steel also has an advantage in that the high CSL frequency was obtained by one-step thermomechanical processing, in contrast with the other GBE processes ${ }^{1,3,7-10)}$ which require several iterations of strong strain plus annealing for favorable GBCD or improvement of material properties. Michiuchi et al. ${ }^{15)}$ have also reported that one-step thermomechanical processing introduced a high frequency 
of CSL boundaries into 316 austenitic stainless steel and consequently decreased the susceptibility to intergranular corrosion significantly.

Intergranular corrosion of stainless steels can be divided into passive and transpassive corrosion, depending on the electrode potential region of the environment. ${ }^{19,20)}$ The previous studies have demonstrated that GBE is effective for preventing intergranular corrosion at passive potentials by sensitization due to intergranular carbide precipitation in 304 and 316 austenitic stainless steels. ${ }^{11,15,16)}$ Meanwhile, intergranular corrosion possibly occurs for stainless steel due to the preferential dissolution of phosphate and/or phosphorus segregated at grain boundaries under corrosion environment at transpassive potentials. ${ }^{21-27)}$ GBE may probably be also effective to suppress the transpassive intergranular corrosion of austenitic stainless steels. The present study aimed to examine the effect of GBE on the transpassive intergranular corrosion of type 304 austenitic stainless steels containing different concentrations of phosphorus.

\section{Experimental Procedures}

The chemical compositions (mass\%) of two 304 austenitic stainless steels used in the present study are shown in Table 1. One of them was an ordinary commercial 304 stainless steel containing $0.027 \%$ phosphorus, termed "high-P". The other one was specially prepared to contain a low phosphorus concentration of $0.001 \%$, termed "low-P". The as-received 304 steels were solution heat treated at $1323 \mathrm{~K}$ for $0.5 \mathrm{~h}$, and termed base materials (BMs). The BMs, $6 \times 10 \times 40 \mathrm{~mm}^{3}$ in size, were thermomechanically processed by a one-step, pre-strain plus annealing process at the similar parameters to the previous study, ${ }^{11)}$ i.e., cold-rolling by $5 \%$ reduction in thickness and subsequent annealing at $1220 \mathrm{~K}$ for $72 \mathrm{~h}$ followed by quenching in cold water.

The frequency of CSL boundaries and GBCD were analyzed by electron backscatter diffraction (EBSD) using a field emission scanning electron microscope (SEM). The frequency of CSL boundaries was cited as a percentage by length on the cross section. Brandon's criterion ${ }^{28)}$ was adopted for the critical deviation in the grain boundary characterization. ${ }^{29)}$ Although the relationship between the grain boundary energy and the $\Sigma$-value is not simple depending on the grain boundary plane, etc., the present authors reported that the grain boundaries with $\Sigma \leq 29 \mathrm{CSL}$ misorientations were prone to show higher resistance to intergranular carbide precipitation and corrosion than the other grain boundaries in a sensitized 304 austenitic stainless steel. $5,30,31)$ Therefore, in the present study, grain boundaries with $\Sigma \leq 29$ were classified as CSL boundaries with low-energy, the others being classified as random boundaries with high energy.

Transpassive intergranular corrosion susceptibility was

Table 1. Chemical compositions of type 304 stainless steels used in this study (mass\%).

\begin{tabular}{ccccccccc}
\hline Materials & $\mathrm{C}$ & $\mathrm{Si}$ & $\mathrm{Mn}$ & $\mathrm{P}$ & $\mathrm{S}$ & $\mathrm{Cr}$ & $\mathrm{Ni}$ & $\mathrm{Fe}$ \\
\hline High-P & 0.058 & 0.59 & 1.05 & 0.027 & 0.006 & 18.47 & 8.47 & Bal. \\
Low-P & 0.058 & 0.60 & 1.05 & 0.001 & 0.001 & 18.60 & 8.44 & Bal. \\
\hline
\end{tabular}

assessed by the Coriou test ${ }^{21,27)}$ to measure the weight loss of the specimens after they were immersed in a boiling $5 \mathrm{~mol} / \mathrm{L} \mathrm{HNO}_{3}+0.15 \mathrm{~mol} / \mathrm{L} \mathrm{Cr}^{6+}$ solution for $10 \mathrm{~h}, 20 \mathrm{~h}$ and $30 \mathrm{~h}$. Before the Coriou test, specimens were heat treated for $24 \mathrm{~h}$ at a temperature of $973 \mathrm{~K}$ to enhance phosphide precipitation, and then all surfaces of the specimens had been polished with \#400 emery paper. After ultrasonic cleaning and drying, the surface area and weight of the specimens were measured with a precision of $0.0001 \mathrm{~mm}^{2}$ and $1 \mathrm{mg}$, respectively. The average corrosion rate was calculated by the weight loss of unit surface area in unit time $\left(\mathrm{g} / \mathrm{m}^{2} \cdot \mathrm{h}\right)$ during every duration of Coriou test. The surface and cross-sectional microstructures of corrosion-tested specimens were observed by optical microscopy (OM).

\section{Results and Discussion}

\subsection{Production of GBEM by Thermomechanical Pro- cessing}

The previous study ${ }^{11}$ has demonstrated that a specific one-step GBE process with slight strain plus anneal resulted in an optimized GBCD with a uniform distribution of a high frequency of CSL boundaries in a type 304 stainless steel. The same GBE process with similar parameters to those of the previous study ${ }^{11)}$ was applied to the high-P and low-P BMs in the present study and achieved optimum GBCDs by $5 \%$ pre-strain annealing at $1220 \mathrm{~K}$ for $72 \mathrm{~h}$ in the specimens which are termed as GBEMs in this paper. Figure 1 shows the EBSD-GBCD maps of the BMs and the

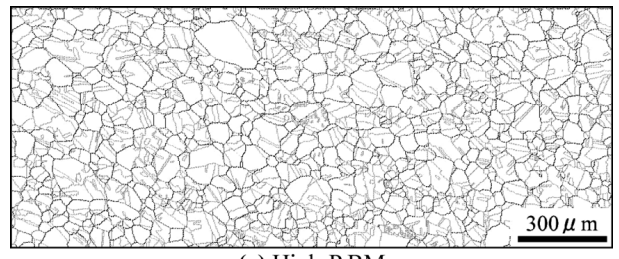

(a) High-P BM

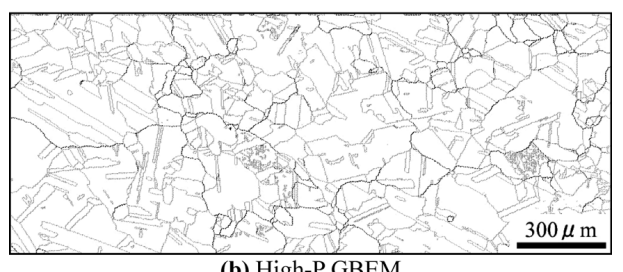

(b) High-P GBEM

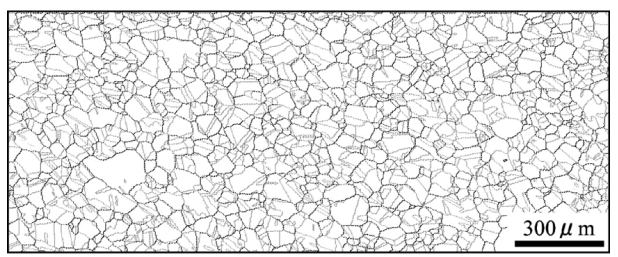

(c) Low-P BM

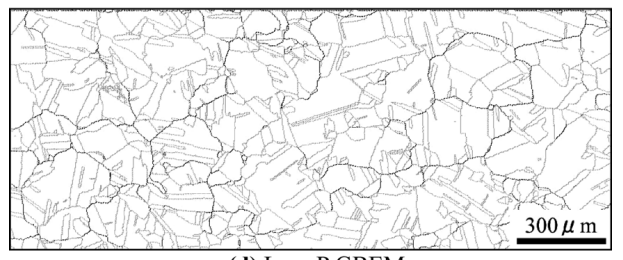

(d) Low-P GBEM

Fig. 1. EBSD-GBCD maps of BMs and GBEMs of high-P $(a, b)$ and low-P (c, d) materials. Black and gray lines indicate random and CSL boundaries, respectively. 

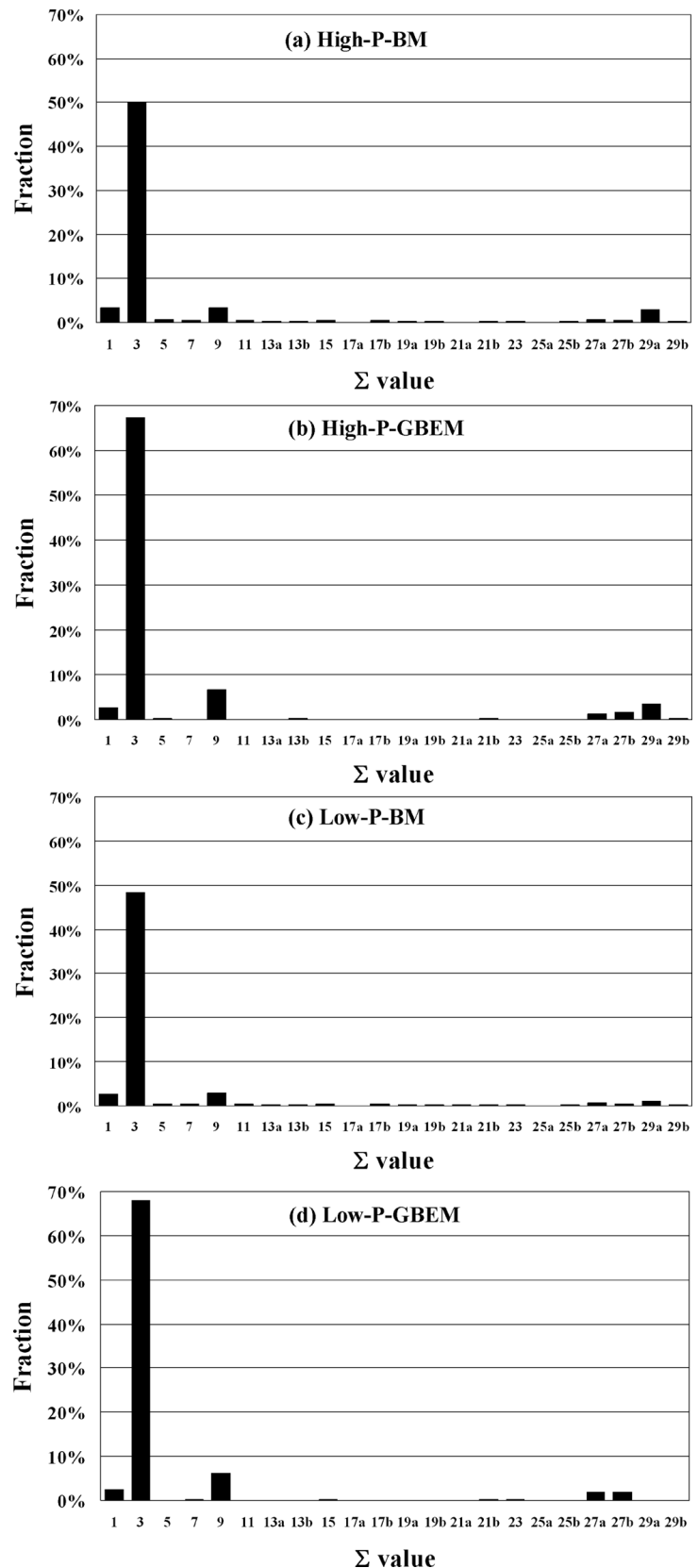

Fig. 2. Fractions of $\Sigma$ boundaries for BMs and GBEMs of high$P(a, b)$ and low-P (c, d) materials.

GBEMs of high-P (a, b) and low-P (c, d) materials. Average grain sizes including all boundaries in Fig. 1 are $19 \mu \mathrm{m}$, $34 \mu \mathrm{m}, 21 \mu \mathrm{m}$ and $40 \mu \mathrm{m}$, for high-P BM (a), high-P GBEM (b), low-P BM (c) and low-P GBEM (d) materials, respectively. The random boundaries drawn by black lines were well connected in the BMs (Figs. 1(a) and 1(c)), while their connectivity was remarkably disrupted by CSL boundaries drawn by gray lines in the GBEMs (Figs. 1(b) and 1(d)). The frequencies of CSL boundaries were about $64 \%$ in the high-P BM and about $60 \%$ in the low-P BM, while about $84 \%$ in the high-P GBEM and about $82 \%$ in the lowP GBEM. The GBE process with the optimum parameters could reproduce the discontinuous random boundary network and higher frequency of CSL boundaries than $82 \%$ in the type 304 stainless steels. ${ }^{16)}$ Figure 2 shows the fractions in length of $\Sigma$ CSL boundaries for BMs and GBEMs of high-P $(a, b)$ and low-P (c, d) materials. Higher fractions of
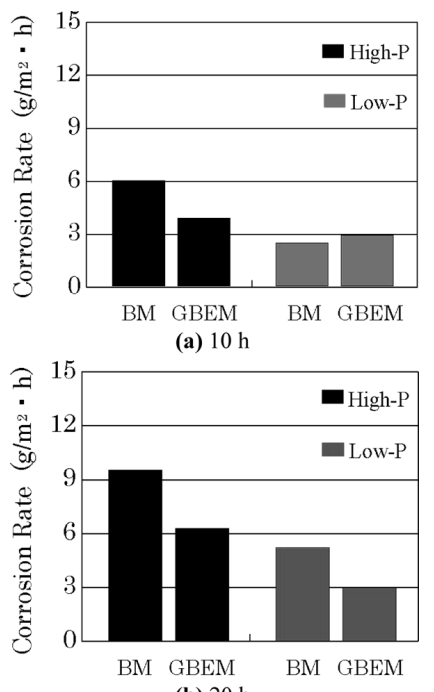

(b) $20 \mathrm{~h}$

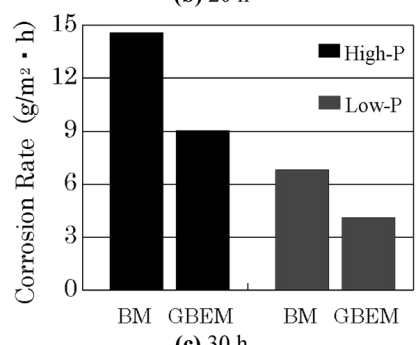

(c) $30 \mathrm{~h}$

Fig. 3. Corrosion rates of BMs and GBEMs of high-P and low-P materials during Coriou test for $10 \mathrm{~h} \mathrm{(a),20} \mathrm{h} \mathrm{(b)} \mathrm{and} 30 \mathrm{~h}$ (c)

$\Sigma 3$ and $\Sigma 9$ boundaries in GBEMs than those in BMs in Fig. 2 suggest frequent formation of annealing twins and active twin-twin reactions during the thermomechanical processing for GBE.

\subsection{Effect of GBE on Transpassive Intergranular Cor- rosion}

The Coriou test was carried out to examine the transpassive intergranular corrosion resistance of the BMs and the GBEMs of high-P and low-P materials. Intergranular corrosion propagates along grain boundaries and causes massloss due to grain dropping from the material surface. The results of the Coriou tests for different durations $(10 \mathrm{~h}, 20 \mathrm{~h}$, $30 \mathrm{~h}$ ) are shown in Fig. 3. Although the corrosion (massloss) rate increased with the test duration in each of the specimens and was higher in high-P material than in low-P one, it should be noted that the corrosion rate was much lower for the GBEM than for the corresponding BM, except in low-P material for the shortest test duration of $10 \mathrm{~h}$ (Fig. 3(a)).

The surface and cross-sectional (perpendicular to coldrolling direction) microstructures after the Coriou tests for $30 \mathrm{~h}$ were observed by OM, as presented in Fig. 4 for BM and GBEM of high-P material and in Fig. 5 for BM and GBEM of low-P material. Although intergranular corrosion is more or less seen on the surfaces of all the specimens (Figs. 4(a), 4(b), 5(a) and 5(b)) and the cross-sectional observations show more significant grain-dropping in high-P specimens (Figs. 4(c) and 4(d)) than in low-P ones (Figs. 5(c) and 5(d)), it should also be noted that much less graindropping is seen for the GBEM (Figs. 4(d) and 5(d)) than 


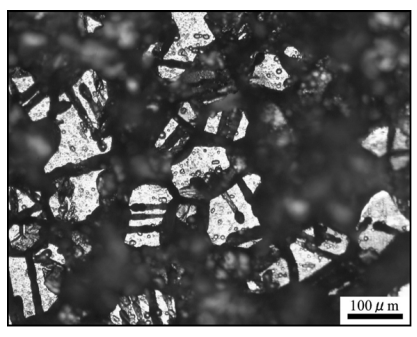

(a) High-P BM surface

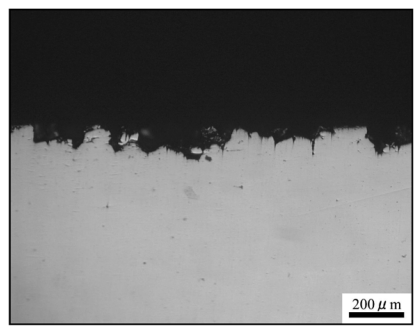

(c) High-P BM cross section

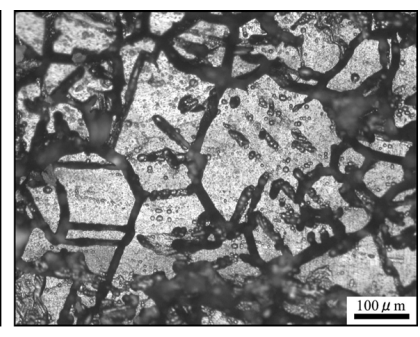

(b) High-P GBEM surface

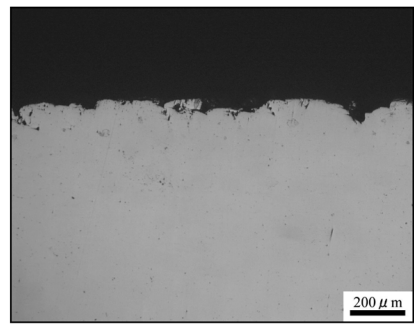

(d) High-P GBEM cross section
Fig. 4. Optical micrographs of surfaces $(a, b)$ and cross sections $(c, d)$ of BM and GBEM of high-P material after the Coriou test for $30 \mathrm{~h}$

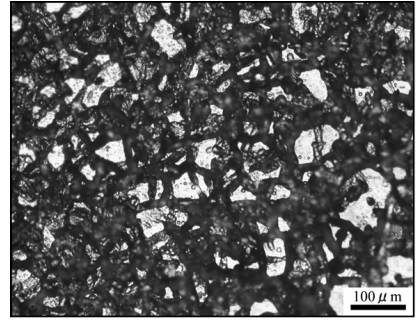

(a) Low-P BM surface

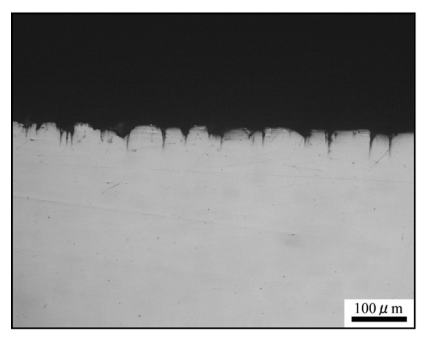

(c) Low-P BM cross section

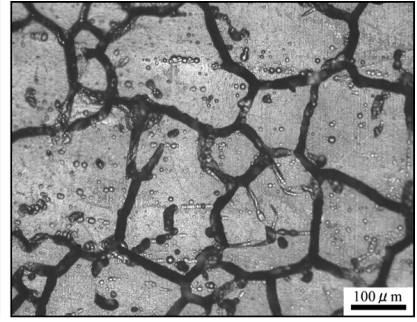

(b) Low-P GBEM surface

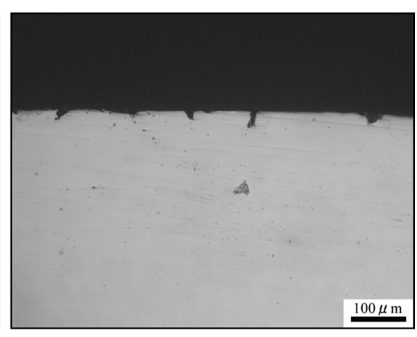

(d) Low-P GBEM cross section
Fig. 5. Optical micrographs of surfaces $(a, b)$ and cross sections (c,d) of BM and GBEM of low-P material after the Coriou test for $30 \mathrm{~h}$

for the BM (Figs. 4(c) and 5(c)) in each of high- and low-P materials. These results suggest that GBE is effective to suppress transpassive intergranular corrosion as well as passive one such as sensitization in 304 austenitic stainless steel. $^{11)}$

\subsection{Percolation of Random Boundaries in GBEM}

Figure 6 shows optical microstructures $(\mathrm{OM})$ and EBSD-GBCD maps in cross sections of BM $(a, b)$ and GBEM (c, d) of high-P material after the Coriou test for $20 \mathrm{~h}$. The EBSD-GBCD maps (Figs. 6(b) and 6(d)) suggest that the intergranular corrosion tends to propagate preferentially along random boundaries indicated by black lines and to be arrested by CSL boundaries indicted by gray lines (some of the $\Sigma$-values are indicted in the figures), and that the high frequency of CSL boundaries in GBEM resists ef-

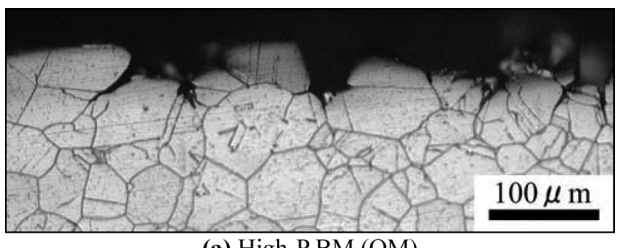

(a) High-P BM (OM)
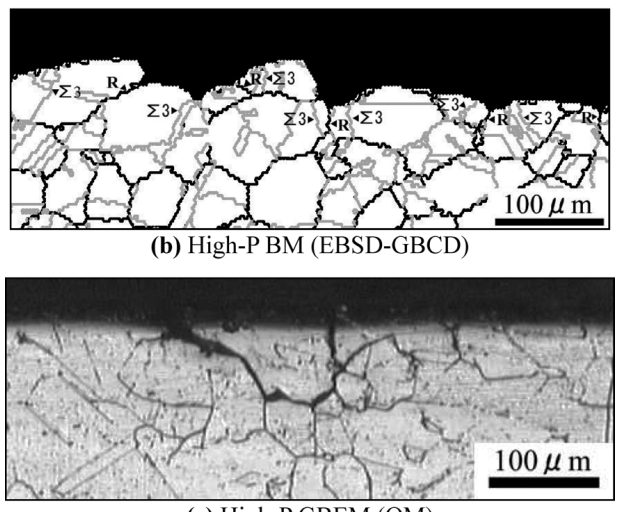

(c) High-P GBEM (OM)

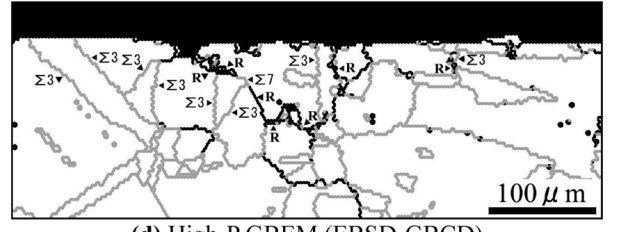

(d) High-P GBEM (EBSD-GBCD)

Fig. 6. Optical microstructures (OM) and EBSD-GBCD maps in cross sections of BM (a,b) and GBEM (c, d) of high-P material after the Coriou test for $20 \mathrm{~h}$. Black and gray lines indicate random and CSL boundaries, respectively, in the EBSD-GBCD maps $(b, d)$.

fectively to the corrosion propagation (Fig. 6(d)) in comparison with the relatively low frequency of CSL boundaries in BM (Fig. 5(b)).

The production mechanism of the high CSL frequency in GBEM during thermomechanical processing has been examined in previous studies. ${ }^{11,15)}$ Active annealing twin events and reactions introduce a large number of lowenergy segments into the initial random boundary network, ${ }^{11,15)}$ and simultaneously, as compared with random boundaries, CSL boundaries are structurally more stable and less reactive with lattice dislocations and other boundaries. $^{32,33)}$ These complex reactions may increase the frequency of CSL boundaries during the twin-induced GBE. ${ }^{15}$ ) Consequently, the GBEM includes a number of $\Sigma 3^{n} \mathrm{CSL}$ boundaries where $n$ is integer. The high CSL frequency in GBEM resulted in remarkable prevention of intergranular corrosion, as shown in Fig. 3. It should be quantified how high CSL frequency must be for effective suppression of intergranular degradation by twin-induced GBE.

The percolation theory is often used in the discussion of intergranular degradation phenomena. ${ }^{34-43)}$ Typically, intergranular corrosion preferentially propagates from the surface into the interior of the material along the random boundaries. The resistance by GBE to intergranular corrosion depends on the degree of connectivity of random boundaries, i.e., less connectivity is more desirable. The degree of connectivity can be quantified using the percolation theory with a cluster of random boundaries. ${ }^{34,35)}$ Schuh et $a l{ }^{34)}$ reported that the maximum length of the random 


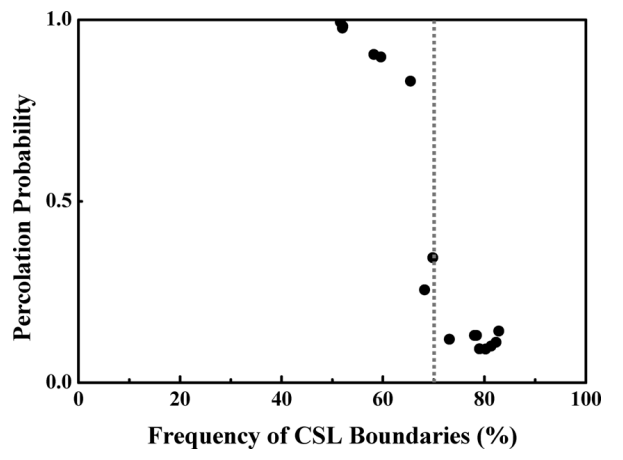

Fig. 7. Relationship between CSL frequency and percolation probability obtained from differently thermomechanically processed 304 austenitic stainless steel (high-P).

boundary cluster $\left(D_{\max }\right)$ is a microstructural predictor of material performance when random boundaries dominate material properties. The ratio of the $D_{\max }$ to the total length of the random boundaries can be approximately regarded as two-dimensional (2-D) percolation probability of random boundaries. ${ }^{44)}$ In the present study, the $D_{\max }$ and total length of random boundaries were measured in a $2 \times 2 \mathrm{~mm}^{2}$ EBSD-GBCD map taken from each thermomechanically processed high-P 304 stainless steel in the same way as in the previous study with 316 steel. $^{15)}$ More than 1000 grains were observed in each of the specimens using the EBSDGBCD map, so the corresponding number of grain boundaries were sampled for statistical discussion. ${ }^{34)}$ The length ratio as percolation probability is shown in relation to the CSL frequency in Fig. 7. This figure suggests that the 2-D percolation threshold is approximately $70 \%$ of the CSL frequency and that obviously low percolation is achieved over the threshold in the 2-D GBCD during the present GBE with 304 stainless steel. Previous studies ${ }^{15,45)}$ have also reported a CSL frequency of around $70 \%$ for the $2-\mathrm{D}$ percolation threshold in austenitic stainless steels $(70 \%$ in $304 \mathrm{~L}$ steel $^{45)}$ and $72 \%$ in 316 steel $^{15)}$ ).

Monte Carlo simulation studies have dealt with grain boundary percolation. ${ }^{35-37)}$ Wells et al. ${ }^{36)}$ estimated that two- and three-dimensional (3-D) percolation thresholds of susceptible grain boundary clusters in an austenitic stainless steel are about $35 \%$ and $77 \%$, respectively, in the frequency of susceptible grain boundaries on the basis of the simple binary random bond percolation theory. The 2-D percolation threshold of about $70 \%$ in the present study is much higher than $35 \%$. Random bond percolation, however, cannot be simply applied to twin-induced GBE because the GBCD produced by twin-induced GBE is under crystallographic constraints at triple junctions according to the $\Sigma$-product rule. ${ }^{46)}$ Schuh et al. ${ }^{35}$ ) showed that as compared with randomly assembled networks, about 50-75\% more resistant boundaries will be required to fragment the susceptible grain boundaries in 2-D GBCD when the $\Sigma$ product rule is adapted to the simulation, which accepts the 2-D percolation threshold of $70 \%$ CSL frequency in 304 stainless steel (Fig. 7). Frary et $a l^{41)}$ estimated the 3-D percolation threshold in crystallographic constrained grain boundary networks to be $80 \%$ in CSL frequency for the twinned microstructure where $\Sigma 3^{n}$ CSL boundaries are special. The high CSL frequencies over $82 \%$ in the present 304 GBEMs exceeded the threshold, even considering that it included about $2 \%$ of non- $\Sigma 3^{n}$ CSL frequency $(\Sigma \leq 29)$. However, it should be noted that the frequency of CSL boundaries is somewhat higher than that of corrosion-resistant boundaries because the CSL boundaries did not always resist corrosion well in the 304 GBEMs as generally mentioned by Randle. ${ }^{47)}$ Therefore, Coriou tests were carried out to experimentally evaluate whether the frequency of transpassive intergranular corrosion-resistant boundaries in the 304 GBEMs exceed the threshold.

The experimental corrosion-test results, as shown in Figs. 3-6, reflect the 3-D percolation of susceptible grain boundaries in the BMs and GBEMs of 304 steels with highand low-P concentrations. The large corrosion rate (Figs. 3(b) and 3(c)) due to the deep intergranular penetration (Figs. 4(c) and 6(a)) in the BM can be explained as being due to the very high percolation probability at $60-64 \%$ of CSL frequencies as the pre-thresholds for 304 steel in Fig. 7, while the much lower corrosion rate (Fig. 3) due to the less grain-dropping (Figs. 4(d) and 6(c)) in the GBEMs may have resulted from the low percolation probability at $82-84 \%$ of the CSL frequency, which is an over-threshold value in Fig. 7. Our previous studies on GBE of 304 and 316 stainless steels demonstrated that a CSL frequency over $85 \%$ resulted in excellent resistance to intergranular corrosion due to sensitization. ${ }^{11,15)}$ The present study on GBE of 304 stainless steels with different $\mathrm{P}$ concentrations revealed that a CSL frequency over $82 \%$ is also significantly effective to suppress transpassive intergranular corrosion. These experimental results for austenitic stainless steels support the theoretical estimation by Frary et al. ${ }^{41)}$ that the 3-D percolation threshold of random boundaries is $80 \%$ of the CSL frequency in austenitic stainless steels. A CSL frequency of over $80 \%$ may assure the very low percolation probability of random boundary networks in the over-threshold region, as well as remarkable suppression of intergranular deterioration during twin-induced GBE of austenitic stainless steels. Although consideration of grain boundary planes $^{47,48)}$ and other factors may probably give the precise frequency of corrosion-resistant boundaries, the frequency of CSL boundaries is an available and statistical parameter to evaluate the degree of GBE at present.

\section{Conclusions}

Optimized one-step thermomechanical-processing of 304 austenitic stainless steels containing different phosphorus concentrations produced 304 GBEMs with a high CSL frequency over $82 \%$. The GBEMs demonstrated much higher resistance to transpassive intergranular corrosion than the corresponding BMs during the Coriou test. A CSL frequency of over $80 \%$ may assure very low percolation probability of random boundary networks in the over-threshold region and remarkable suppression of intergranular deterioration during twin-induced GBE of 304 austenitic stainless steels.

\section{Acknowledgement}

The Iron and Steel Institute of Japan Research Promotion Grant is gratefully acknowledged. This work was also supported by a Grant-in-Aid for Scientific Research (A) (No. 21246104), a Grant-in-Aid for Science Research (S) (No. 
19106013), a Grant-in-Aid for Science Research (S) (No. 19106017), and a grant from the Global COE Program "Materials Integration (International Center of Education and Research), Tohoku University", MEXT, Japan. The authors wish to thank to Dr. M. Shimada, Dr. M. Michiuchi, Mr. S. Sato, Mr. M. Miyagi, Mr. T. Oyamada and Mr. A. Honda for their technical assistance and useful discussion.

\section{REFERENCES}

1) J. Le Coze and M. Biscondi: Can. Metall. Q., 13 (1974), 59.

2) H. Kokawa, T. Watanabe and S. Karashima: Philos. Mag. A, 44 (1981), 1239.

3) X. R. Qian and Y. T. Chou: Philos. Mag. A, 45 (1982), 1075.

4) H. Kokawa, C. H. Lee and T. H. North: Metall. Trans. A, 22 (1991), 1627.

5) H. Kokawa, M. Shimada and Y. S. Sato: JOM, 52 (2000), No. 7, 34.

6) T. Watanabe: Res Mech., 11 (1984), 47.

7) G. Palumbo, E. M. Lehockey and P. Lin: JOM, 50 (1998), No. 2, 40.

8) S. Spigarelli, M. Cabibbo, E. Evangelista and G. Palumbo: Mater. Sci. Eng. A, 352 (2003), 93.

9) M. Qian and J. C. Lippold: Acta Mater, 51 (2003), 3351.

10) V. Randle and H. Davies: Metall. Mater. Trans. A, 33 (2002), 1853.

11) M. Shimada, H. Kokawa, Z. J. Wang, Y. S. Sato and I. Karibe: Acta Mater, 50 (2002), 2331.

12) H. Y. Bi, H. Kokawa, Z. J. Wang, M. Shimada and Y. S. Sato: Scr. Mater, 49 (2003), 219.

13) H. Kokawa, M. Shimada, Z. J. Wang, Y. S. Sato and M. Michiuchi: Key Eng. Mater., 261-263 (2004), 1005.

14) H. Kokawa: J. Mater. Sci., 40 (2005), 927.

15) M. Michiuchi, H. Kokawa, Z. J. Wang, Y. S. Sato and K. Sakai: Acta Mater, 54 (2006), 5179.

16) H. Kokawa, M. Shimada, M. Michiuchi, Z. J. Wang and Y. S. Sato: Acta Mater, 55 (2007), 5401.

17) W. Z. Jin, S. Yang, H. Kokawa, Z. J. Wang and Y. S. Sato: J. Mater. Sci. Technol., 23 (2007), 785.

18) V. Randle: Acta Mater, 52 (2004), 4067.

19) S. Abe, M. Kaneko and T. Mizunuma: Tetsu-to-Hagané, 79 (1993), 706.

20) G. L. Song: Corros. Sci., 47 (2005), 1953.

21) J. S. Armijo: Corrosion, 24 (1968), 24.
22) K. T. Aust: Trans. Metall. Soc. AIME, 245 (1969), 2117.

23) J. E. Truman: J. Appl. Chem., 4 (1954), 273.

24) M. A. Streicher: J. Electrochem. Soc., 106 (1959), 161.

25) J. S. Armijo: Corrosion, 21 (1965), 235.

26) C. L. Briant: Corrosion, 36 (1980), 497.

27) A. R. Perrin and K. T. Aust: Mater. Sci. Eng., 51 (1981), 165.

28) D. G. Brandon: Acta Metall., 14 (1966), 1479.

29) H. Kokawa, T. Watanabe and S. Karashima: Scr. Metall., 21 (1987), 839.

30) H. Kokawa and T. Kuwana: Trans. Jpn. Weld. Soc., 23 (1992), 73.

31) H. Kokawa, T. Koyanagawa, M. Shimada, Y. S. Sato and T. Kuwana: Properties of Complex Inorganic Solids 2, ed. by A. Meike et al., Kluwer Academic/Plenum Publishers, New York, (2000), 17.

32) H. Kokawa, T. Watanabe and S. Karashima: J. Mater. Sci., 18 (1983), 1183.

33) H. Kokawa, T. Watanabe and S. Karashima: Scr. Metall., 17 (1983), 1155 .

34) C. A. Schuh, M. Kumar and W. E. King: Acta Mater, 51 (2003), 700 .

35) C. A. Schuh, R. W. Minich and M. Kumar: Philos. Mag., 83 (2003), 711.

36) D. B. Wells, J. Stewart, A. W. Herbert, P. M. Scott and D. E. Williams: Corrosion, 45 (1989), 649.

37) R. W. Minich, C. A. Schuh and M. Kumar: Phys. Rev. B, 66 (2002), 052101 .

38) M. A. Gaudett and J. R. Scully: Metall. Mater. Trans. A, 25 (1994), 775 .

39) V. Y. Gertsman and K. Tangri: Acta Mater., 45 (1997), 4107.

40) P. Volovitch, V. Traskine and L. Barrallier: Z. Metallkd., 95 (2004), 215.

41) M. Frary and C. A. Schuh: Philos. Mag., 85 (2005), 1123.

42) M. Frary and C. A. Schuh: Acta Mater, 53 (2005), 4323.

43) J. A. Basinger, E. R. Homer, D. T. Fullwood and B. L. Adams: Scr. Mater, 53 (2005), 959.

44) J. Hoshen and R. Kopelman: Phys. Rev. B, 14 (1976), 3438.

45) S. Tsurekawa, S. Nakamichi and T. Watanabe: Acta Mater., 54 (2006), 3617.

46) K. Miyazawa, Y. Iwasaki, K. Ito and Y. Ishida: Acta Crystallogr. A, 52 (1996), 787.

47) V. Randle: Scr. Mater., 54 (2006), 1011.

48) V. Randle and R. Jones: Mater. Sci. Eng. A, 524 (2009), 134. 